\title{
Biodegradation of nitrilotriacetic acid (NTA) in the absence of oxygen
}

\author{
T. Egli and H.-U. Weilenmann
}

Swiss Federal Institute for Water Resources and Water Pollution Control, Swiss Federal Institutes of Technology, CH-8600 Dübendorf (Switzerland), 30 December 1985

Summary. A microbial culture able to grow in the absence of oxygen with nitrilotriacetate (NTA) as the sole source of carbon and energy was enriched from river sediment. Growth was strictly dependent on the presence of nitrate and the results indicate that nitrate was exclusively used as the electron acceptor and was reduced to dinitrogen $\left(\mathrm{N}_{2}\right)$. The stoichiometry of anaerobic NTA degradation by the enrichment culture was determined.

Key words. Nitrilotriacetate (NTA); biodegradation; enrichment culture; denitrification; sewage treatment.

One of the main causes of the widespread eutrophication of lakes and rivers is the extensive use of phosphates in washing powders and agricultural fertilizers ${ }^{1}$. In order to reduce such effects, the Swiss Federal Council has passed an amendment, effective from July 1986, prohibiting the use of phosphates in washing powders. One of the potential substitutes for sodium tripolyphosphates (STPP) in domestic detergents is nitrilotriacetic acid (NTA). Being a highly effective complexing agent, NTA will bind primarily to calcium, magnesium and heavy metal ions under conditions occurring in natural waters and wastewater treatment plants. It is expected that the increased use of NTA will result in an enhanced concentration of this compound in natural waters which are used as sources for drinking water production. For this reason, in spite of the fact that NTA has been employed in Canada since 1970 without apparent negative results, there is considerable concern, e.g., in West Germany, particularly in the Ruhr region, that NTA usage could result in significant remobilization of heavy metals at present bound in considerable concentrations in both soils and sediments. As a consequence NTA/heavy metal complexes could be transported through the process steps involved in drinking water production. The microbial degradation of NTA in the presence of oxygen is well documented for freshwater environments, soil and biotreatment plants as well as for pure cultures of NTA-utilizing bacteria. The relevant literature is cited in refs 2 and 3 . The catabolic pathway for NTA was studied in two Pseudomonas spp. ${ }^{4-6}$ and it was shown that in both bacteria the first step in NTA oxidation is catalyzed by an $\mathrm{O}_{2} / \mathrm{NADH}$-dependent mono-oxygenase.

The disappearance of NTA in complex systems such as anaerobic digesters, and sediments in the absence of oxygen, is also documented $^{7-9}$. It proceeds at a markedly slower rate than aerobic degradation and is often only partially complete. Until now, anaerobic degradation of NTA by a pure culture has only been demonstrated by Enfors and Molin ${ }^{10}$. Because the research was apparently discontinued the data reported by these authors is rather incomplete and neither the taxonomy of the bacterium isolated nor the enzymology of anaerobic NTA degradation have been elucidated. Because aerobic NTA utilization, in all strains investigated so far, involves an $\mathrm{O}_{2}$-dependent mono-oxygenase it must be assumed that degradation under anoxic conditions must proceed via an alternative metabolic pathway.

Materials and methods. The enrichment medium contained per liter: $\mathrm{MgSO}_{4} \cdot 7 \mathrm{H}_{2} \mathrm{O}, 1.0 \mathrm{~g} ; \mathrm{CaCl}_{2} \cdot 2 \mathrm{H}_{2} \mathrm{O}, 0.20 \mathrm{~g} ; \mathrm{Na}_{2} \mathrm{HPO}_{4} \cdot 2$ $\mathrm{H}_{2} \mathrm{O}, 0.41 \mathrm{~g} ; \mathrm{KH}_{2} \mathrm{PO}_{4}, 0.26 \mathrm{~g} ; \mathrm{NaNO}_{3}, 1.40 \mathrm{~g}$; trace element solution according to Widdel ${ }^{11}, 1.0 \mathrm{ml}$; pyridoxin $\cdot \mathrm{HCl}, 100 \mu \mathrm{g}$; $50 \mu \mathrm{g}$ of each thiamine $\mathrm{HCl}$, riboflavin, nicotinic acid, D-Capantothenic acid, p-amino benzoic acid, lipoic acid, nicotinamide, vitamin $\mathrm{B}_{12}$; biotin, $20 \mu \mathrm{g}$; folic acid, $20 \mu \mathrm{g}$. The enrichment culture was started with an NTA concentration of 20 $\mathrm{mg} \mathrm{l}^{-1}$ in the inflowing medium and, after complete utilization of NTA was observed in the culture vessel, its concentration in the reservoir was increased stepwise to $1.0 \mathrm{~g} \mathrm{l}^{-1}$. 


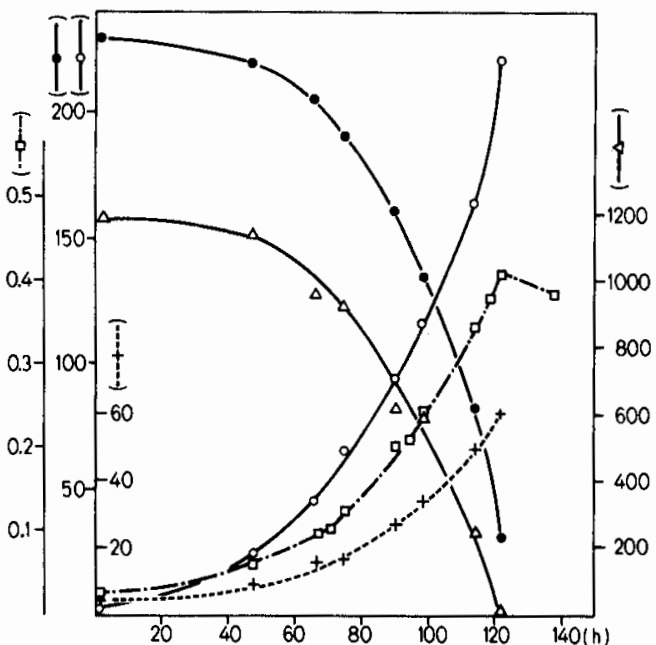

Growth of a batch enrichment culture with NTA and $\mathrm{NO}_{3}{ }^{-}$in the absence of oxygen; temperature, $25^{\circ} \mathrm{C}$; $\mathrm{pH}, 6.8$; growth $\left(\mathrm{OD}_{546}\right), \square$; NTA concentration $\left(\mathrm{mg} \mathrm{l}^{-1}\right), \Delta ;$ itrate concentration $\left(\mathrm{mg} \mathrm{N} / 1^{-1}\right), \bullet ;$ ammonium concentration ( $\mathrm{mg} \mathrm{N}^{-1}$ ), +; dinitrogen produced ( $\mathrm{mg} \mathrm{N} \mathrm{N}_{2}$ [1 culture fluid] $\left.{ }^{-1}\right), O$.

NTA was measured by differential pulse polarography (Polarecord E 505/506, Metrohm, Switzerland). The detection limit was $1 \mathrm{mg} \mathrm{^{-1 }}$. $\mathrm{N}_{2}$ was determined gas chromatographically using a Shimadzu GC 8A fitted with a thermal conductivity detector (column, molecular sieve $5 \AA, 80 / 100$ mesh, $2.5 \mathrm{~m}$; oven temperature, $70^{\circ} \mathrm{C}$; carrier gas $\mathrm{He}, 40 \mathrm{ml} \mathrm{min}{ }^{-1}$ ). $\left.\mathrm{NO}_{3}\right|^{-}-\mathrm{N} \mid$ and $\left.\mathrm{NH}_{4}\right|^{+}-\mathrm{N} \mid$ were both measured with an automatic nitrogen analyzer (Skalar, Netherlands). A C, N, H-Analyzer Model 185 (F \& M Scientific Corporation, Avondale, $\mathrm{Pa}$ ) was used to measure the carbon and nitrogen content of whole cells. Dissolved organic carbon was determined with a TOC/DOC-analyzer (TOCOR 2, Maihak, FRG).

Results. In our laboratory a culture was enriched under anoxic conditions (the vessel was continuously flushed with $\mathrm{O}_{2}$-free helium) in a chemostat $\left(D=0.02 \mathrm{~h}^{-1}\right)$ from sediment taken from the River Glatt using a synthetic medium with nitrate and sulfate as potential electron acceptors and NTA as the only source of carbon and energy. This enrichment culture degraded NTA completely and the growth pattern achieved in batch culture with an inoculum taken from the continuous enrichment culture is shown in the figure. For both chemostat and batch enrichment cultures the balances for carbon and nitrogen varied within $100 \pm 10 \%$ and these results indicated that NTA degradation by the mixed culture can be described by the following stoichiometric equation (1):

$$
\begin{aligned}
\mathrm{C}_{6} \mathrm{~N}(\mathrm{NTA}) & +2.8 \mathrm{NO}_{3}{ }^{-} \mathrm{N} \\
& \rightarrow \mathrm{CN}_{0.2} \text { (cells) }+0.8 \mathrm{NH}_{4}{ }^{+}-\mathrm{N}+5 \mathrm{CO}_{2}-\mathrm{C}+1.4 \mathrm{~N}_{2}
\end{aligned}
$$

Omission of nitrate from the culture medium resulted in no growth indicating that the utilization of NTA in this enrichment culture is dependent on the availability of nitrate as an electron acceptor. When the culture was growing exponentially no significant accumulation of $\mathrm{NO}_{2}^{-}\left(<0.1 \mathrm{mg} \mathrm{l}^{-1} \mathrm{NO}_{2}^{-}-\mathrm{N}\right)$ was detected. Accumulation of low concentrations of $\mathrm{NO}_{2}^{-}$was only observed under transient growth conditions, i.e. stepwise increase of substrate concentration in the feed to the chemostat enrichment culture, and in all cases less than $1 \%$ of the nitrate consumed by the cells was converted to nitrite. With respect to the capacity to degrade NTA completely in the absence of oxygen and the stoichiometry of NTA degradation as reported in equation (1) the continuous enrichment culture has been stable for more than half a year. It has been reported earlier by Enfors and Molin ${ }^{10}$ that the presence of nitrate was essential for their isolate to grow with NTA in the absence of oxygen. However, neither the metabolic fate of nitrogen from $\mathrm{NO}_{3}{ }^{-}$nor the fate of nitrogen from NTA was traced. There is clear evidence from the data presented here, that nitrate was used by the enrichment culture exclusively as an electron acceptor and was reduced to dinitrogen, whereas NTA was the sole source of cellular carbon and nitrogen. However, as a $\mathrm{C} / \mathrm{N}$-source for microbial growth, NTA is a substrate containing excess nitrogen, and therefore, the cells excreted surplus nitrogen from NTA in the form of ammonia. Under both chemostat and batch culture conditions 75$85 \%$ of the nitrogen transported into the cells with the NTA molecule accumulated in the culture medium during anaerobic growth. This is in contrast to aerobic NTA-utilizing microbes where the cells excrete only $55-60 \%$ of the nitrogen during growth with NTA as the sole source of carbon and nitrogen (Egli, unpublished results). Under the conditions tested anaerobic degradation of NTA by the enrichment culture was complete and no significant formation of accumulating carbonaceous products ( $<5 \%$ of total carbon from NTA) was found. Attempts will be made to isolate the microbe(s) capable of degrading NTA under denitrifying growth conditions from the enrichment culture and to identify the enzymes which are involved in the breakdown of NTA in the absence of oxygen. Because all denitrifying microbes known so far are facultative anaerobes, the isolate should also be able to grow aerobically with NTA. Isolation of such a versatile bacterium would be most attractive for wastewater-treatment processes and could yield information concerning the reasons why all aerobically isolated NTA-utilizing bacteria possess NTA-mono-oxygenase.

Acknowledgments. We wish to thank G. Hamer for his help and support throughout this study. The project is financed by EAWAG (project No. 20-842)

1 Stumm, W., and Morgan, J.J., in: Aquatic Chemistry, 2nd edn, pp. 700-711. John Wiley and Sons, New York 1981.

2 Anderson, R.L., Bishop, W.E., and Campbell, R. L., CRC Crit. Rev. Toxic. 15 (1985) 1.

3 Janicke, W., Fischer, W. K., Gudernatsch, H., Günther, K.O., Opgenorth, H.-J., de Oude, N. T., and Wunderlich, M., in: NTA. Studie über die aquatische Umweltverträglichkeit von Nitrilotriacetat (NTA), pp. 139-165. Eds H. Bernhardt et al. Verlag Hans Richarz, Sankt Augustin 1984.

4 Cripps, R.E., and Noble, A. S., Biochem. J: 136 (1973) 1059.

5 Tiedje, J.M., Mason, B. B., Warren, C. B., and Malec, E. J., Appl. Microbiol. 25 (1973) 811

6 Firestone, M.K., and Tiedje, J.M., Appl. Envir. Microbiol. 35 (1978) 955 .

7 Klein, S. A., J. Wat. Pollut. Control Fedn 46 (1974) 78

8 Moore, L., and Barth, E. F., J. Wat. Pollut. Control Fedn 48 (1976) 2406.

9 Stephenson, T., Perry, R., and Lester, J.N., Water Res. 17 (1983) 1337.

10 Enfors, S.-O., and Molin, N., Water Res. 7 (1973) 881 and 889.

11 Pfennig, N., Widdel, F., and Trüper, H.G., in: The Procaryotes, pp. 926-940. Eds M.P. Starr et al. Springer Verlag, Berlin 1981.

$0014-4754 / 86 / 091061-02 \$ 1.50+0.20 / 0$

(C) Birkhäuser Verlag Basel, 1986 